OPEN ACCESS

Edited by:

Vinood B. Patel,

University of Westminster, UK

Reviewed by:

Odete A. B. Da Cruz E. Silva, Universidade de Aveiro, Scotland

Ramesh Kandimalla,

Emory University, USA

*Correspondence:

Pascal Kienlen-Campard pascal.kienlen-

campard@uclouvain.be,

Stefan N. Constantinescu stefan.constantinescu@bru.licr.org

${ }^{\dagger}$ These authors have contributed equally to this work.

Received: 22 February 2016 Accepted: 25 April 2016

Published: 10 May 2016

Citation:

DecockM, Stanga S, Octave J-N, Dewachter I, Smith SO, Constantinescu SN

and Kienlen-Campard P (2016)

Glycines from the APP

GXXXG/GXXXA Transmembrane

Motifs Promote Formation

of Pathogenic A $\beta$ Oligomers in Cells.

Front. Aging Neurosci. 8:107.

doi: 10.3389/fnagi.2016.00107

\section{Glycines from the APP GXXXG/GXXXA Transmembrane Motifs Promote Formation of Pathogenic A $\beta$ Oligomers in Cells}

\author{
Marie Decock', Serena Stanga', Jean-Noël Octave1, Ilse Dewachter', Steven O. Smith², \\ Stefan N. Constantinescu ${ }^{3 *}$ and Pascal Kienlen-Campard ${ }^{1 *}$ \\ ${ }^{1}$ CEMO-Alzheimer Dementia, Institute of Neuroscience, Université Catholique de Louvain, Brussels, Belgium, ${ }^{2}$ Department \\ of Biochemistry and Cell Biology, Stony Brook University, Stony Brook, NY, USA, ${ }^{3}$ Ludwig Institute for Cancer Research - \\ de Duve Institute, Université Catholique de Louvain, Brussels, Belgium
}

Alzheimer's disease (AD) is the most common neurodegenerative disorder characterized by progressive cognitive decline leading to dementia. The amyloid precursor protein (APP) is a ubiquitous type I transmembrane (TM) protein sequentially processed to generate the $\beta$-amyloid peptide $(A \beta)$, the major constituent of senile plaques that are typical $A D$ lesions. There is a growing body of evidence that soluble $A \beta$ oligomers correlate with clinical symptoms associated with the disease. The A $\beta$ sequence begins in the extracellular juxtamembrane region of APP and includes roughly half of the TM domain. This region contains GXXXG and GXXXA motifs, which are critical for both TM protein interactions and fibrillogenic properties of peptides derived from TM $\alpha$-helices. Glycine-to-leucine mutations of these motifs were previously shown to affect APP processing and A $\beta$ production in cells. However, the detailed contribution of these motifs to APP dimerization, their relation to processing, and the conformational changes they can induce within $A \beta$ species remains undefined. Here, we describe highly resistant $A \beta 42$ oligomers that are produced in cellular membrane compartments. They are formed in cells by processing of the APP amyloidogenic C-terminal fragment (C99), or by direct expression of a peptide corresponding to $A \beta 42$, but not to $A \beta 40$. By a point-mutation approach, we demonstrate that glycine-to-leucine mutations in the $G^{29} X X X G^{33}$ and $G^{38} X X X A^{42}$ motifs dramatically affect the $A \beta$ oligomerization process. G33 and G38 in these motifs are specifically involved in A $\beta$ oligomerization; the G33L mutation strongly promotes oligomerization, while G38L blocks it with a dominant effect on G33 residue modification. Finally, we report that the secreted A $A 42$ oligomers display pathological properties consistent with their suggested role in $A D$, but do not induce toxicity in survival assays with neuronal cells. Exposure of neurons to these A $\beta 42$ oligomers dramatically affects neuronal differentiation and, consequently, neuronal network maturation.

Keywords: Alzheimer's disease, amyloid precursor protein, beta-amyloid peptide, oligomers, GXXXG motifs, neuronal differentiation 


\section{INTRODUCTION}

The amyloid precursor protein (APP) is a ubiquitously expressed type 1 transmembrane protein (Kang et al., 1987; Selkoe, 2004) whose processing in the amyloidogenic pathway leads to the production of the $\beta$-amyloid peptides (A $\beta)$. A $\beta$ peptides are the major constituent of the senile plaques, a hallmark of AD (Glenner and Wong, 1984). Mutations responsible for inherited $\mathrm{AD}$ cases (early onset or familial $\mathrm{AD}$ ) are located in the genes coding for APP or the presenilins (Kandimalla et al., 2012). The presenilins (PS1 and PS2) are the catalytic subunits of $\gamma$-secretase, a multiprotein complex that cleaves the APP $\beta$-C-terminal fragment ( $\beta C T F$ or $C 99)$ to generate $A \beta$ in the last step of the amyloidogenic pathway. APP or PS mutations typically result in imbalanced $A \beta$ production and an increased $A \beta 42 / A \beta 40$ ratio (Selkoe, 2004). These observations led to the amyloid cascade hypothesis, predicting that the initial steps of $\mathrm{AD}$, which trigger a series of pathogenic events, are related to $A \beta$ production and clearance (Hardy and Allsop, 1991). Although this hypothesis remains a matter of debate (Herrup, 2015), experimental lines of evidence from cellular models, transgenic animals and patient brain samples has been overwhelming (Hardy, 2009). Less is known about the cellular mechanisms that control the formation of pathological $A \beta$ oligomers. Both cellular trafficking, particularly endocytosis, and posttranslational modification like phosphorylation have been involved in $\mathrm{A} \beta$ production and accumulation (Feyt et al., 2005, 2007).

Alzheimer's disease onset and progression appears to be directly linked to the accumulation of abnormally folded $A \beta$ assemblies. Although fibrillogenic species were first suggested to be responsible for $\mathrm{AD}$-induced neurotoxic events, growing evidence shows that soluble $A \beta$ oligomers are more strongly correlated with clinical symptoms associated with the disease (Lesne et al., 2006; McDonald et al., 2010; Kandimalla et al., 2011, 2014). Different $A \beta$ oligomers have been described, ranging from dimers to dodecamers and high molecular weight assemblies. These assemblies can be classified between an "offpathway" or an "on-pathway" with respect to fibrillization. Soluble oligomers have been characterized in transgenic mouse brains (Kawarabayashi et al., 2001; Lesne et al., 2006; Shankar et al., 2009; Pham et al., 2010), and to some extent in brains of AD patients (Hayden and Teplow, 2013). Still, the key toxic $A \beta$ species remain poorly defined in terms of both molecular structure and relevance to the mechanisms underlying long term potentiation defects and neuronal cell death.

Structural studies on $\mathrm{A} \beta$ assemblies have largely come from in vitro measurements of synthetic peptides corresponding to $A \beta 40$ and $A \beta 42 . A \beta 40$ is the predominant isoform ( $90 \%)$ generated by $\gamma$-secretase cleavage, while $\mathrm{A} \beta 42(10 \%)$ is the major component of amyloid plaques. Monomeric $A \beta$ adopts predominantly a random coil structure. Monomers associate into small MW oligomers (dimers - hexamers) that are able to combine into larger MW oligomers, which in turn laterally associate into protofibrils ( $\mathrm{Fu}$ et al., 2015). The conversion of protofibrils to fibrils involves a transition to cross- $\beta$-structure. The conversion implies association of the short hydrophobic
LVFF sequence with the hydrophobic C-terminus of A $\beta$ (Fu et al., 2015).

Glycines appear to be important in both the turn region between $\beta$-strands and in the $\mathrm{C}$-terminal $\beta$-sheet. Glycines have a critical impact on peptide aggregation, facilitating the association of $\beta$-sheets during fibril formation in vitro (Liu et al., 2005; Sato et al., 2006). Fibrillization of synthetic $A \beta$ peptides containing glycine-to-leucine ( $G$ to $L$ ) mutations has been monitored in vitro (Kim and Hecht, 2006; Hung et al., 2008). Treatment of neuronal cells showed a reduction of toxicity for mutated peptides when compared to non-mutated $A \beta$. Reduced toxicity correlated with a reduction of small oligomeric species in solution and increased rates of fibril formation (Hung et al., 2008). Using synthetic peptides, Harmeier et al. (2009) highlighted G33 as critical for the generation of $A \beta 42$ assemblies. Mutation of G33 promoted rapid $\mathrm{A} \beta$ oligomerization by conformational changes that favored the formation of high molecular weight oligomers, which were less pathogenic than $A \beta 42$. In contrast, a G37L substitution dramatically reduced $A \beta$ toxicity as measured by cell dysfunction, cell death, synaptic alteration in primary neurons and transgenic Caenorhabditis elegans models (Fonte et al., 2011). Important limitations in studies using synthetic $A \beta$ peptides to generate oligomers in vitro are their exact relevance to $\mathrm{AD}$ pathology. The soluble oligomers are formed in vitro at relatively high concentrations. At lower concentrations, which may be more representative of physiological conditions, the monomer oligomer equilibrium shifts toward the monomeric state, which is non-toxic and presumably is more easily cleared from the brain. The structure and stability of soluble oligomers that are produced physiologically have consequently been of considerable interest.

G33 and G37 lie within the hydrophobic C-terminus of the A $\beta$ peptide and represent the third APP TM GXXXG motif. GXXXG motifs occur abundantly in the TM helices of membrane proteins where they facilitate TM helix dimerization and close apposition. Strikingly, C99 has three consecutive GXXXG motifs, followed by a GXXXA motif, all of which have been implicated in dimerization and regulation of C99 processing by the $\gamma$-secretase complex (Munter et al., 2007; Kienlen-Campard et al., 2008). The structural role that the GXXXG motif plays critically depends on the structural element in which it is located and the exposure to water. In aqueous environments, glycine is able to adopt multiple conformations due to the lack of a side chain and the ability of the backbone $\mathrm{NH}$ to hydrogen bond to water (glycine is known as a helix breaker in soluble proteins and often occurs in turn sequences). In hydrophobic TM helices, glycines in a GXXXG motif fall on one face of a TM $\alpha$-helix and facilitate helix-helix dimerization. The TM helices are energetically favored due to intrahelical backbone hydrogen bonding in the absence of water and helix association is favored due to interhelical van der Waals and hydrogen bonding interactions. Interestingly, in $\beta$-sheets the glycines in a GXXXG motif lie on one face of the $\beta$-sheet and when the $\beta$-strands are parallel and in-register, they form long surface grooves that facilitate sheet-to-sheet packing that excludes water (Sato et al., 2006). This multifaceted nature of glycine is highlighted in its role at each stage of the process from 
TM helix to soluble oligomer to fibril. The same multifaceted nature of glycine may underlie the aggregation of the human prion protein, which also contains three consecutive GXXXG motifs.

We have further investigated the role of the GXXXG/GXXXA motifs in dimerization of $\mathrm{C} 99$ and oligomerization of $\mathrm{A} \beta$ produced by living cells. We found that mutation of the critical G33 and G38 residues, respectively, in the $\mathrm{G}^{29} \mathrm{XXXG}^{33}$ and $\mathrm{G}^{38} \mathrm{XXXA}^{42}$ motifs did not affect dimerization of C99. In contrast, mutations in these motifs triggered the assembly of $\mathrm{A} \beta 42$, in living cells, into $\sim 28 \mathrm{kDa}$ oligomers corresponding to the expected molecular weight of $A \beta$ hexamers. Similar oligomers are not detected with constructs producing only $A \beta 40$. The $A \beta 42$ oligomers generated by living cells are resistant to temperature and denaturing conditions. They are enriched in membrane-bounded compartments, and released in the extracellular medium. Finally, we showed that $A \beta 42$ oligomers generated by living cells did not display neurotoxic effects, but greatly affected neuronal differentiation and the formation of neuronal networks.

\section{MATERIALS AND METHODS}

\section{Chemicals and Reagents}

Restriction enzymes, Taq DNA polymerase, all culture media, penicillin-streptomycin solution, HAT and Lipofectamine ${ }^{\circledR}$ transfection reagents, Nu-Page ${ }^{\circledR}$ Novex $^{\circledR} \quad 4-12 \%$ Bis-Tris gels and buffers were from Life Technology Corporation (Carlsbad, CA, USA). Fetal bovine serum (FBS) for culture media was purchased from Thermo Scientific (Rockford, IL, USA). Analytical grade solvents, salts and poly-L-lysine were from Sigma-Aldrich (St Louis, MO, USA). Protease inhibitor cocktail was purchased from Roche (Basel, Switzerland). BCA protein assay kit was from Pierce (Rockford, IL, USA). Nitrocellulose membranes were obtained from GE Healthcare (Fairfield, CT, USA). ECL reagents were obtained from Perkin Elmer Inc. (Waltham, MA, USA). The following primary antibodies were used: anti-Amyloid $\beta$ Antibody, clone W0-2 (EMD Millipore, Billerica, MA, USA), Anti-Amyloid Precursor Protein C-terminal, anti-MAP2 and anti-actin antibody (Sigma-Aldrich, St Louis, MO, USA), and antiGLuc antibody (New England Biolabs, Ipswich, MA, USA). Fluorescent nucleic acid stain DAPI was obtained from SigmaAldrich (St Louis, MO, USA). Secondary antibodies coupled to HRP were obtained from Amersham Bioscience (Uppsala, Sweden) and fluorescent secondary antibody coupled to Alexa fluorochromes from Life Technology Corporation (Carlsbad, CA, USA).

\section{Cells Lines and Cell Culture}

Chinese hamster ovary $(\mathrm{CHO})$ cell lines were grown in Ham's F-12 medium. The media was supplemented with $10 \%$ of FBS and penicillin-streptomycin solution (10 units$10 \mu \mathrm{g})$. All cell cultures were maintained at $37^{\circ} \mathrm{C}$ in a humidified atmosphere $\left(5 \% \mathrm{CO}_{2}\right)$. Mouse neuroblastoma $\times$ Rat glioma hybrid cell lines (NG108-15) were grown in DMEM supplemented with 10\% FBS, 2\% HAT, a mixture of hypoxanthine, aminopterin and thymidine, and antibiotics. Differentiation of NG108-15 cells was induced by switching from regular medium to $1 \%$ FBS medium (Stanga et al., 2015).

\section{Plasmids, Cloning, and Site-Directed Mutagenesis}

C99, C42 mutants and various C-terminally truncated constructs of C99 were obtained by Quick-change site-specific mutagenesis (Stratagene, La Jolla, CA, USA) as previously described (Ben et al., 2012b). The plasmids expressing APP fragments fused to humanized Gaussia luciferase (hGluc) halves were obtained by PCR amplification of APP sequences encoded by expression vectors previously described (Decock et al., 2015). All constructs were verified by full sequencing (Macrogen Europe, Amsterdam, The Netherlands).

\section{Cell Transfection and Conditioning}

Chinese hamster ovary cells were transfected with Lipofectamin reagent $24 \mathrm{~h}$ after seeding following manufacturer's instructions. Plasmids expressing the split-luciferase proteins were cotransfected in a 1:1 ratio. The control plasmid (mock) used was the corresponding empty vector. $48 \mathrm{~h}$ after transfection, media were collected, treated with protease inhibitors cocktail (Roche) and stored at $-20^{\circ} \mathrm{C}$ for ECLIA assay. Cells were harvested and lysed in sample buffer $(125 \mathrm{mM}$ TrisHCl pH 6.8, glycerol $20 \%$ and SDS 4\%) supplemented with protease inhibitor cocktail. Protein concentrations were measured by the BCA protein assay kit from Pierce (Rockford, IL, USA) prior to Western blotting.

Transfected $\mathrm{CHO}$ cell culture media have been used as source of oligomers to treat NG108-15 cells at days 1 and 3 of differentiation. One day after transfection, $\mathrm{CHO}$ cells were maintained in medium without FBS. The $\mathrm{CHO}$ conditioned media enriched in oligomers were mixed (1:1 ratio) to NG10815 cells differentiation medium ( $1 \%$ FBS). Treated NG10815 cells were fixed and processed for immunocytochemistry (day 5).

\section{Western Blotting}

Proteins $(10 \mu \mathrm{g})$ from cell lysates or culture media $(20 \mu \mathrm{l})$ were heated for $10 \mathrm{~min}$ at $70^{\circ} \mathrm{C}$ in loading buffer (lysis buffer supplemented with $0.5 \mathrm{M}$ DTT and staining Nupage blue $\mathrm{e}^{\mathrm{TM}}$ ), separated in $4-12 \%$ Nupage $^{\mathrm{TM}}$ bis-Tris gel and transferred for $2 \mathrm{~h}$ at $30 \mathrm{~V}$ onto nitrocellulose membranes. Ponceau Red staining was used to check gel loading and transfer accuracy. After blocking (5\% non-fat milk in PBS), membranes were incubated overnight at $4{ }^{\circ} \mathrm{C}$ with the primary antibodies: antiAmyloid $\beta$ Antibody, clone W0-2 (1/2,500), Anti-Amyloid Precursor Protein, C-terminal antibody (1/2,000), anti-GLuc antibody $(1 / 2,000)$. Membranes were washed with PBS-Tween $(0.005 \%)$ and incubated with the secondary antibodies antimouse $(1: 10,000)$ or anti-rabbit $(1: 10,000)$ coupled to peroxidase prior to ECL detection from GE Healthcare (Little Chalfont, UK). Signals were quantified with a Gel Doc 2000 imaging system 
coupled to Quantity one $\mathrm{T}^{\mathrm{TM}}$ software from Bio-Rad (Hercules, CA, USA).

\section{Gaussia Luciferase Assay}

Samples were aliquoted in $5 \mathrm{ml}$ polystyrene round-bottom tubes at a final concentration of $10 \mu \mathrm{g}$ of protein in $20 \mu \mathrm{l}$ in Luciferase Cell Lysis Buffer (Promega, Madison, WI, USA). Native coelenterazine was reconstituted as a stock solution of $1 \mathrm{mg} / \mathrm{ml}$ in methanol (stored frozen), diluted $30 \mathrm{~min}$ prior reading in DMEM without phenol red and used at a final concentration of $20 \mu \mathrm{M}$. $50 \mu \mathrm{l}$ of coelenterazine was added to tubes and luminescence directly measured on a Sirius Luminometer (Berthold, Pforzheim, Germany).

\section{A $\beta$ Quantification}

$\mathrm{A} \beta 38, \mathrm{~A} \beta 40$, and $\mathrm{A} \beta 42$ peptides were quantified in the cell medium as previously described (Hage et al., 2015) using the $\mathrm{A} \beta$ multiplex electro-chemiluminescence immunoassay (ECLIA; Meso Scale Discovery, Gaithersburg, MD, USA). Cells were conditioned in serum-free medium for $16 \mathrm{~h}$; cell medium was collected and $A \beta$ were quantified according to the manufacturer's instructions with the human $\mathrm{A} \beta$ specific $6 \mathrm{E} 10$ multiplex assay.

\section{Cell Survival Assay}

Cell viability (NG108-15 cells) was assessed with a MTS assay after $24 \mathrm{~h}$ of treatment, according to manufacturer's instruction (Promega, Madison, WI, USA). Plates were measured at $490 \mathrm{~nm}$ using a microplate spectrophotometer Victor X3 Multilabel Plate Reader (PerkinElmer, Waltham, MA, USA).

\section{Immunocytochemistry}

Cells were seeded on 12-well plates previously incubated with poly-L-lysine $(10 \mathrm{mg} / \mathrm{ml})$. Prior to staining, cells were rinsed twice with Opti-MEM ${ }^{\circledR}$ (Life Technology Corporation) and fixed with $4 \%$ paraformaldehyde (PFA) for $15 \mathrm{~min}$. After three washes in PBS, cells were permeabilized with PBS1X/0.3\% Triton100X for $30 \mathrm{~min}$ and blocked in PBS1X/fetal bovine serum 5\%/0.1\% Triton $100 \mathrm{X}$ for $30 \mathrm{~min}$. Primary antibody MAP2 (1:500) was prepared in the blocking solution and incubated $\mathrm{O} / \mathrm{N}$ at $4^{\circ} \mathrm{C}$. After three washes in PBS, cells were incubated with secondary antibody (Goat anti-mouse Alexa 488, 1:500 in blocking solution) and DAPI (1:2000) for $1 \mathrm{~h}$ at $4^{\circ} \mathrm{C}$. After three washes in PBS, cells were stored in PBS-azide $0.1 \%$ at $4^{\circ} \mathrm{C}$. Pictures were acquired with an Evos fluorescence microscope (Advanced Microscopy Group, Mill Creek, WA, USA).

\section{Statistical Analysis}

The number of samples (n) in each experimental condition is indicated in figure legends. The data were analyzed using GraphPad Prism software by analysis of variance (ANOVA) followed by unpaired $t$-test (two experimental conditions) or by Bonferroni's Multiple Comparison tests (more than two experimental conditions).

\section{RESULTS}

\section{Expression of APP C-Terminal Fragments Leads to the Accumulation of Oligomeric A $\beta$ Peptides}

In our previous work we reported that expression of C99 (corresponding to the $\beta$-CTF of APP) leads to the formation of an oligomer, which is detected in denaturating gels as a higher molecular weight band (around $25 \mathrm{kDa}$ ). This band was thought to contain dimers of C99 (Kienlen-Campard et al., 2008), but also -possibly- oligomers of $A \beta$ or other peptides, as well as a mix of C99 and truncated C99 peptides.

In order to characterize the nature of this higher molecular weight band, we expressed in CHO cells different APP constructs: human APP695 (neuronal isoform of APP), C99 (the amyloidogenic $\beta$ C-terminal stub) and $\mathrm{C} 42$, which corresponds to the sequence of human $A \beta 42$, that we engineered by adding a stop codon after residue 42 of $\mathrm{A} \beta$. Both $\mathrm{C} 99$ and $\mathrm{C} 42$ are fused to the APP signal peptide to ensure proper targeting to the secretory pathway. Similar constructs were generated by introducing a stop codon after residue 40 of $\mathrm{A} \beta$ to generate $\mathrm{C} 40$, or by fusing Gaussia luciferase moieties to the C-terminus of C99 to measure its dimerization by a split protein assay (Decock et al., 2015). All these constructs are depicted in Figure 1.

As previously reported, $\beta$ CTFs are barely detectable upon APP expression (Figure 2), the vast majority of APP being processed by the non-amyloidogenic pathway in cells (Haas et al., 1995). C99 expression (corresponding to the $\beta$-CTF) led to the detection of a monomeric band and the previously reported higher molecular weight band (Figure 2A). Strikingly, C42 expression produced a similar high molecular weight band, whereas no band corresponding to monomeric C42 was detected under these conditions. Of note, this higher molecular weight band was not detected in APP-expressing cell lysates. We previously suggested (Kienlen-Campard et al., 2008) that this band could correspond to C99 dimers, but the molecular weight $(\sim 25-30 \mathrm{kDa})$ observed here is not consistent with this idea (Figure 2A). Importantly, the oligomeric band detected was not recognized by an antibody directed against the APP C-terminus that recognizes C99 and APP CTFs (Figure 2A). Sub-cellular fractionation experiments showed that the oligomeric band is enriched in vesicular compartments (MLP) but barely absent from the soluble fractions (Figure 2B), strongly suggesting that the oligomers -like C99- are either membrane associated, or present in a cell membrane-bounded compartment but not in the cytosol. The same oligomeric bands were revealed by Western blotting in the culture medium of cells expressing either C99 or C42 (Figure 3A), but they were not detectable in the medium of cells expressing full-length APP. We measured the production of soluble $A \beta$ in the culture media by the highly sensitive ECLIA multiplex A $\beta$ assay, which detects soluble $A \beta 38 / \mathrm{A} \beta 40 / \mathrm{A} \beta 42$ monomeric isoforms in the same sample (Hage et al., 2013, 2015). As previously shown, soluble monomeric $A \beta$ was readily detected in culture media of APP- and C99-expressing cells, with A $\beta 40$ being the most abundant isoform. C99 constructs produced 35 times more A $\beta$ than full length APP (Figure 3B). Strikingly, 


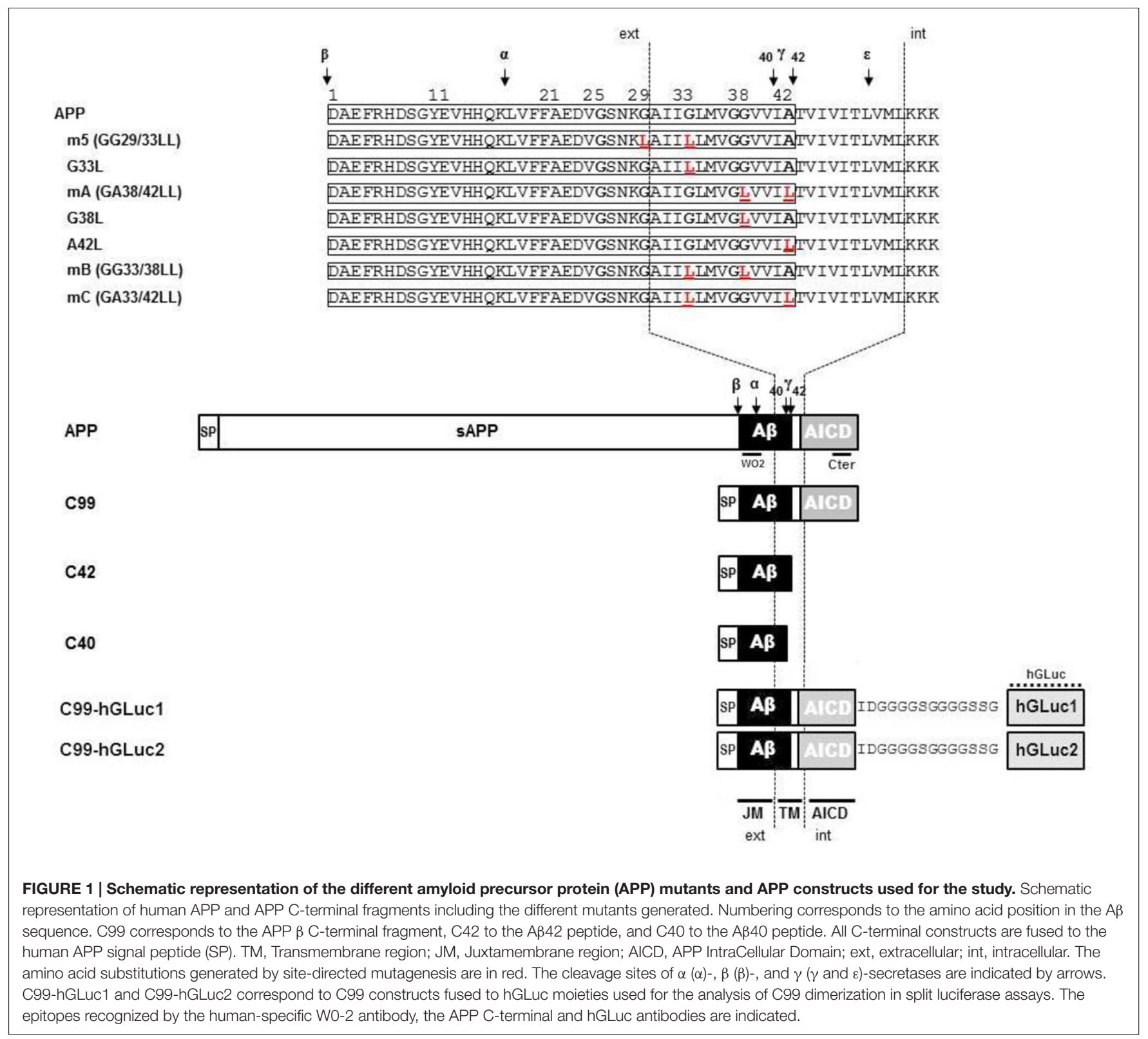

the $\mathrm{C} 42$ construct did not produce detectable $\mathrm{A} \beta$, except very low amounts of $A \beta 38$. Due to the specificity of the assay (soluble monomeric $A \beta$ isoforms), this suggested that only oligomeric $A \beta$ isoforms were generated by C42-expressing cells, in line with the higher molecular weight bands detected by an anti-human $\mathrm{A} \beta$ antibody in the same media (Figure 3A).

We next investigated whether the oligomeric bands detected in cells could correspond to oligomeric $A \beta$ recaptured from the culture medium. We used conditioned media of C42-expressing cells to treat non-transfected cells for $48 \mathrm{~h}$. Media and cells were collected and analyzed after treatment (Figure 4). The $\sim 30 \mathrm{kDa}$ band was still present in the culture medium after treatment, indicating its stability. No similar signal was found in the lysates of treated cells, in contrast to those of C42-expressing cells. This indicated the oligomers detected were primarily produced in cells and not recaptured from the culture medium where they are also present.

Together, these results strongly suggested that the high MW band could correspond to oligomeric $A \beta 42$ peptides, but did not formally exclude that they are formed by the assembly of other $A \beta$ isoforms (e.g., the major $A \beta 40$ isoform) or truncated APP C-terminal fragments. To test this hypothesis we expressed $\mathrm{C} 40$ constructs in cells, which correspond to the $\mathrm{A} \beta 40$ sequence. C40-expressing cells did not produce the oligomers found in C42expressing cells (Supplementary Figure S1). This indicates that the oligomeric bands observed are produced by $\mathrm{A} \beta 42$ - but not A $\beta 40$-expressing constructs. To further confirm this hypothesis, bands around $30 \mathrm{kDa}$ were excised from gels and subjected to nano liquid chromatography (nano-LC) coupled to tandem mass spectrometry (MS/MS). The peptides identified correspond to 
A

Total cell lysates
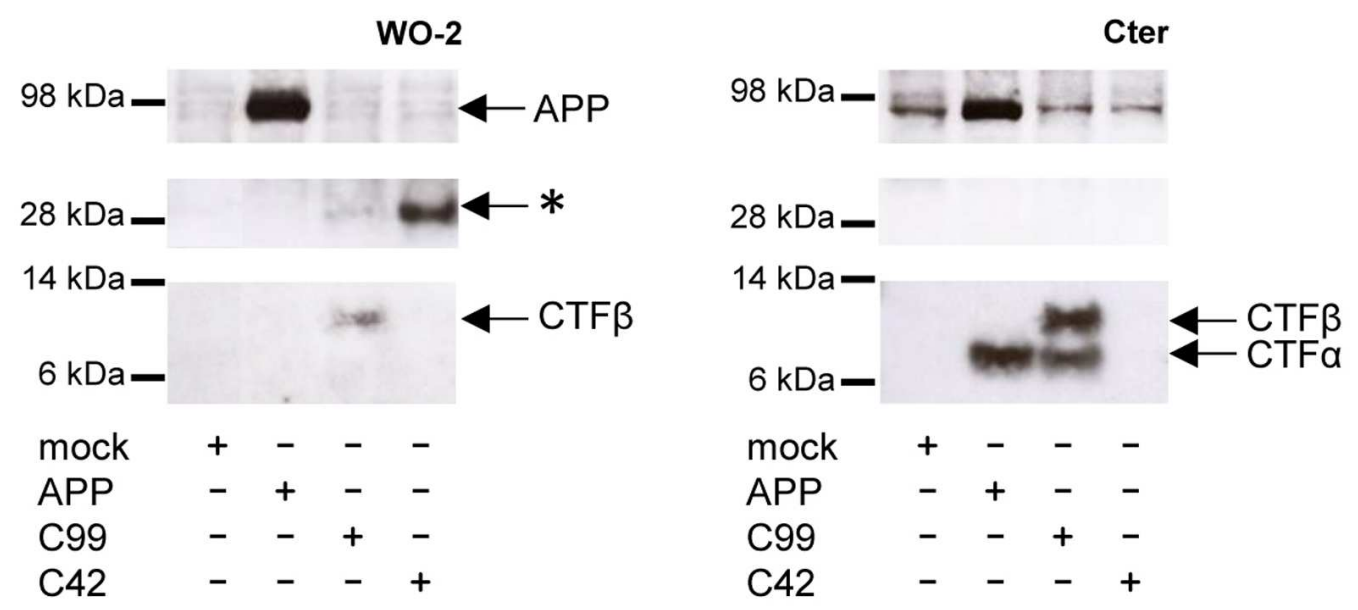

B

\section{Cell fractions}

WO-2

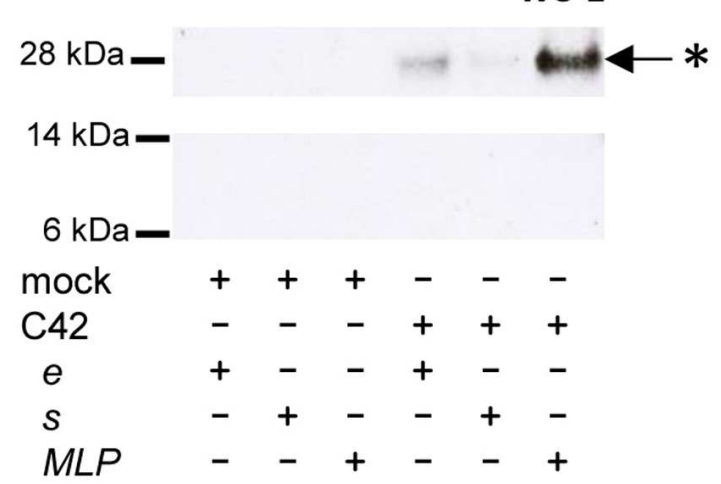

FIGURE 2 | Detection of oligomeric bands in cells expressing C99 and C42. (A) Expression of APP, C99 and C42 in CHO cells analyzed in total cell lysates by Western blotting with the W0-2 antibody (left panel) and the APP C-terminal antibody (right panel). The presence of APP, $\beta$ CTF (C99) and $\alpha$ CTF are indicated by arrows. The star $\left({ }^{*}\right)$ indicates the presence of an unexpected band at $\sim 30 \mathrm{kDa}$. (B) Cell fractions from C42- (left panel) and C99- (right panel) transfected cells were analyzed by Western blotting with the WO-2 antibody. Total cell lysates (e) were fractionated into soluble (s) and membrane-enriched vesicular fractions (MLP). The presence of the higher molecular weight band $(*)$ is indicated by arrows.

human $\mathrm{A} \beta$ sequences (Supplementary Figure S2). No other APP fragments (e.g., from the C-terminus) were identified in these gel samples, even in C99-expressing cells. Thus, we can conclude that the oligomers detected in transfected cells are indeed $A \beta$ oligomers, and more precisely A $\beta 42$ oligomers.

\section{Mutations of Glycine Residues Present in GXXXG on GXXXA Motifs Are Critical for the $A \beta$ Oligomerization Process}

We previously reported that the oligomeric bands identified here as $\mathrm{A} \beta 42$ oligomers were more abundant using C99 constructs mutated in the GXXXG motifs (Kienlen-Campard et al., 2008). In our initial hypothesis, GXXXG mutations induced rotations in the TM helical regions that form stable associations through the GXXXA interface, strengthening dimerization of the APP transmembrane domain (TMD). We mutated the glycine and alanine residues within the $\mathrm{G}^{29} \mathrm{XXXG}^{33} / \mathrm{G}^{38} \mathrm{XXXA}^{42}$ motifs (Figure 5A) to study their contribution to C99 dimerization and $A \beta$ oligomerization. The level of the $A \beta$ oligomeric band was highly increased in cells expressing C99 mutated in the central GXXXG motif (GG29/33LL, referred to as m5) with respect to cells expressing non-mutated C99, but the size of the oligomers remained the same (Figure 5B). Strikingly, the GA38/42LL mutation (referred to as $\mathrm{mA}$ ) abolished $\mathrm{A} \beta$ oligomer production, and mutations affecting $\mathrm{G}^{29} \mathrm{XXXG}^{33}$, $\mathrm{G}^{33} \mathrm{XXXG}^{37}$ and $\mathrm{G}^{38} \mathrm{XXXA}^{42}$ motifs (referred to as $\mathrm{mB}$ and $\mathrm{mC}$ ) produced intermediate levels of oligomers. We analyzed 
A

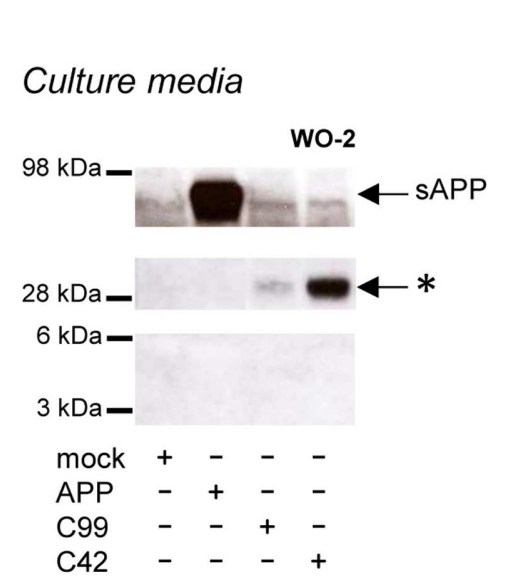

B

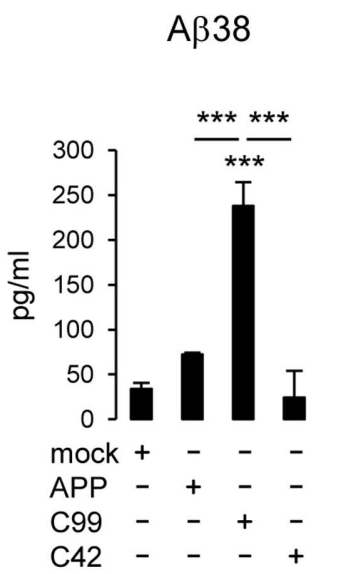

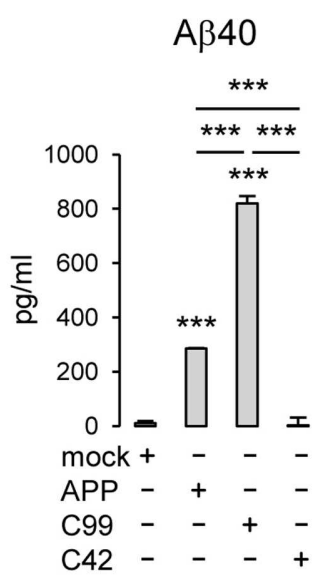

FIGURE 3 | Detection of oligomeric bands and measurement of A $\beta$ in the extracellular medium of cells expressing C99 and C42. (A) Culture media of $\mathrm{CHO}$ cells expressing APP, C99, and C42 were analyzed by Western blotting using the W0-2 antibody. The $\sim 30 \mathrm{kDa}$ oligomer band $\left({ }^{*}\right)$ detected in culture media -similar to the one observed in cell lysates- is indicated by an arrow. (B) Soluble monomeric A 338 , A $\beta 40$, and A 42 were quantified by ECLIA in the culture media of transfected cells. Values (means \pm SEM) given in $\mathrm{pg} / \mathrm{ml}$ are representative of three independent experiments $\left(n=3\right.$ in each experiment). ${ }^{* * *} p<0.001,{ }^{*} p<0.05$, as compared to control (mock-transfected cells).

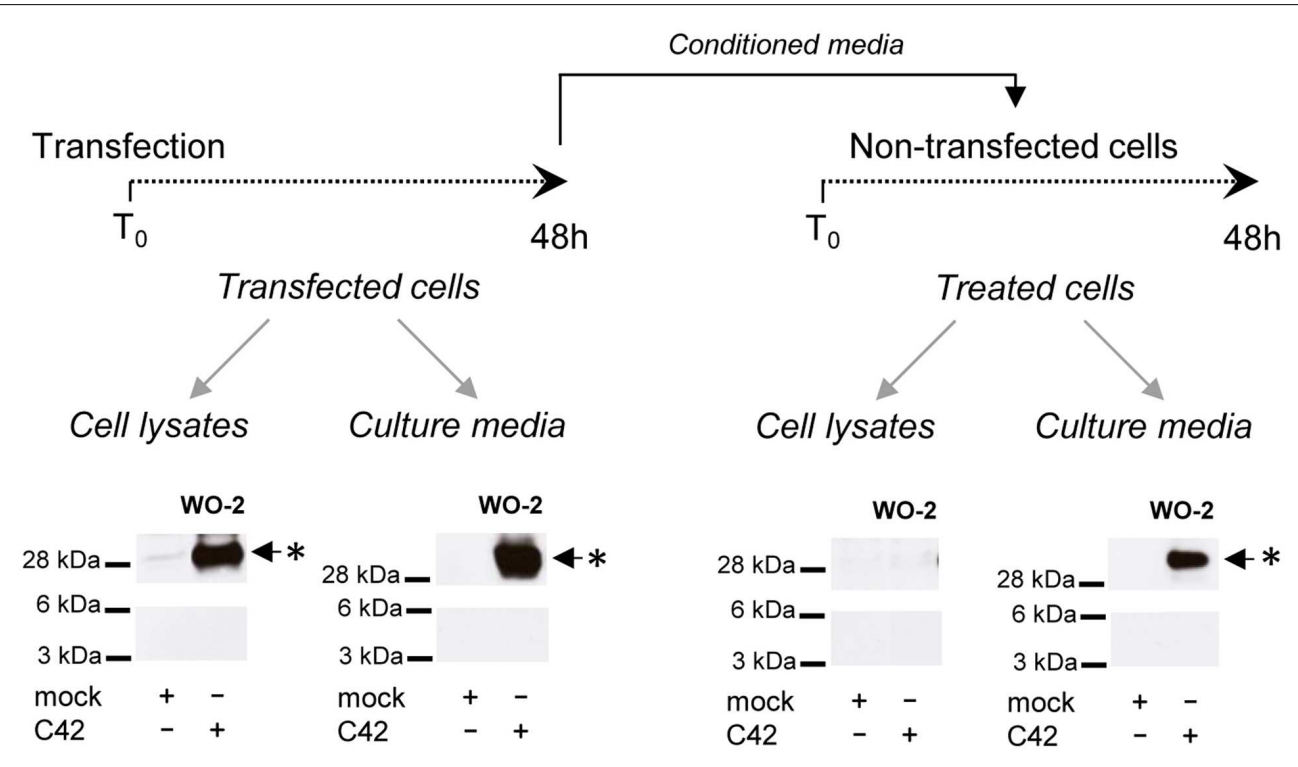

FIGURE 4 | Oligomers detected in cells and not re-captured from the culture medium. $\mathrm{CHO}$ cells were either transfected by the C42 construct (transfected cells) or treated (treated cells) for $48 \mathrm{~h}$ with the conditioned culture medium of C42-transfected cells (mock, non-transfected), as depicted on the top of the figure. The cell lysates and culture media of transfected and treated cells were recovered and analyzed by Western blotting with the W0-2 antibody. The $\sim 30 \mathrm{kDa}$ oligomer band $(*)$ detected in cell lysates and culture media is indicated by an arrow.

the contribution to oligomer formation of key G/A residues in the $\mathrm{G}^{29} \mathrm{XXXG}^{33} / \mathrm{G}^{38} \mathrm{XXXA}^{42}$ motifs. The single G33L mutation was sufficient to induce the oligomerization profile observed with m5 (GG23/33LL). In that context (G33L), mutation of small residues from the $\mathrm{G}^{38} \mathrm{XXXA}^{42}$ interface $(\mathrm{mB}=\mathrm{GG} 33 / 38 \mathrm{LL}$ and $\mathrm{mC}=\mathrm{GA} 33 / 42 \mathrm{LL})$ reduced the oligomerization promoted by the mutation of the critical G33 residue (Figure 5C). We found that these oligomeric bands did not result from changes in C99 dimerization (Munter et al., 2007; Kienlen-Campard et al.,
2008; Ben et al., 2012a). Dimerization measured by a highly sensitive split protein assay (Decock et al., 2015) was found to be equivalent for C99, C99 m5, and C99 mA (Figures 5D,E), whereas oligomeric bands are abundant in C99 m5 but not in C99 mA cell lysates (Figure 5B). Altogether, this indicated that mutations of glycine residues could play a critical but dual role in $A \beta$ production, without major changes in overall dimerization of C99. This idea was further addressed by expressing mutants of C42 in cells. Identical mutations to those studied in the 
A

C99

$$
\text { ext TM }
$$

C42

DAEFRHDSGYEVHHQKLVFEAEDVGSNKGÁ I IGLMVGGVVIATVIVITLVML'KKK..........QMQN

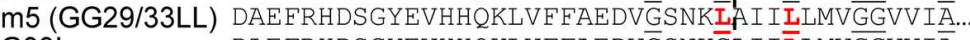

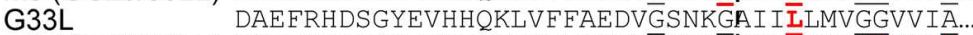

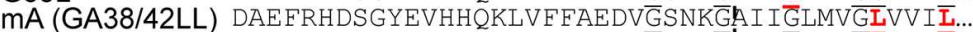

G38L DAEFRHDSGYEVHHQKLVFFAEDVG SNKG $A I I \bar{G} L M V \overline{G L} V V I \bar{L}$...

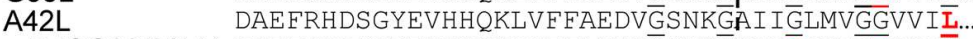

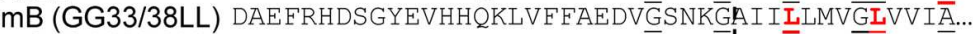

B

mC (GA33/42LL) DAEFRHDSGYEVHHQKLVFFAEDV $\bar{G} S N K \bar{G} A I I \bar{L} L M V \overline{G G V V I \bar{L}}$...
C

Cell lysates

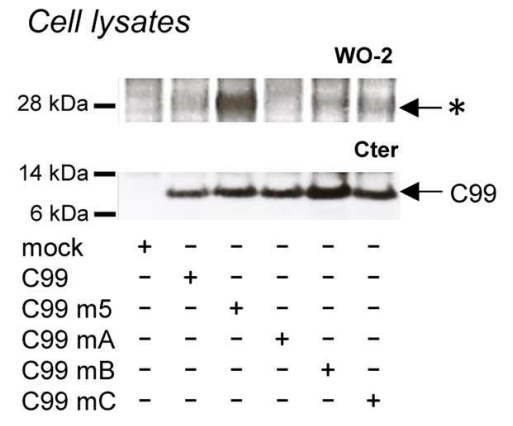

D

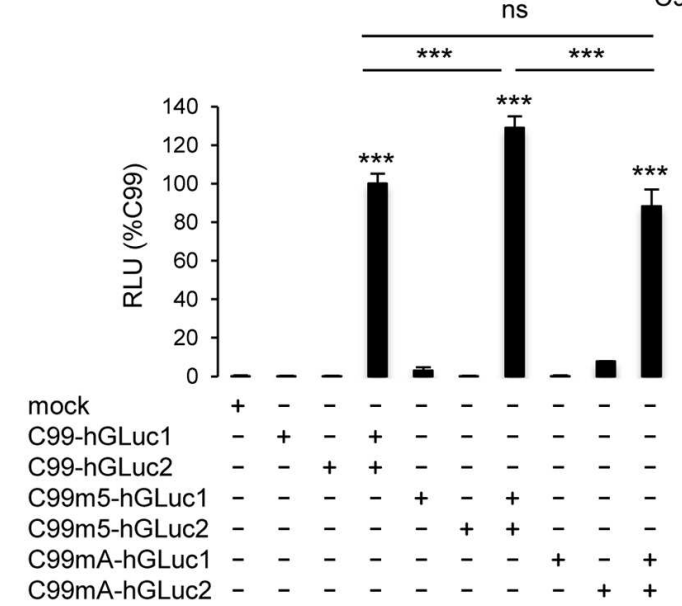

E

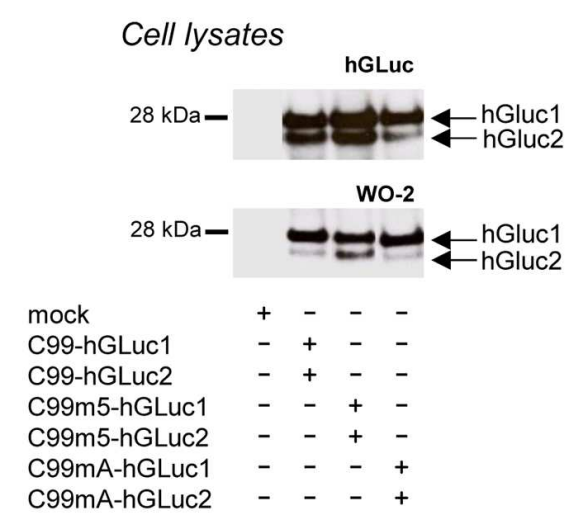

$\mathbf{F}$
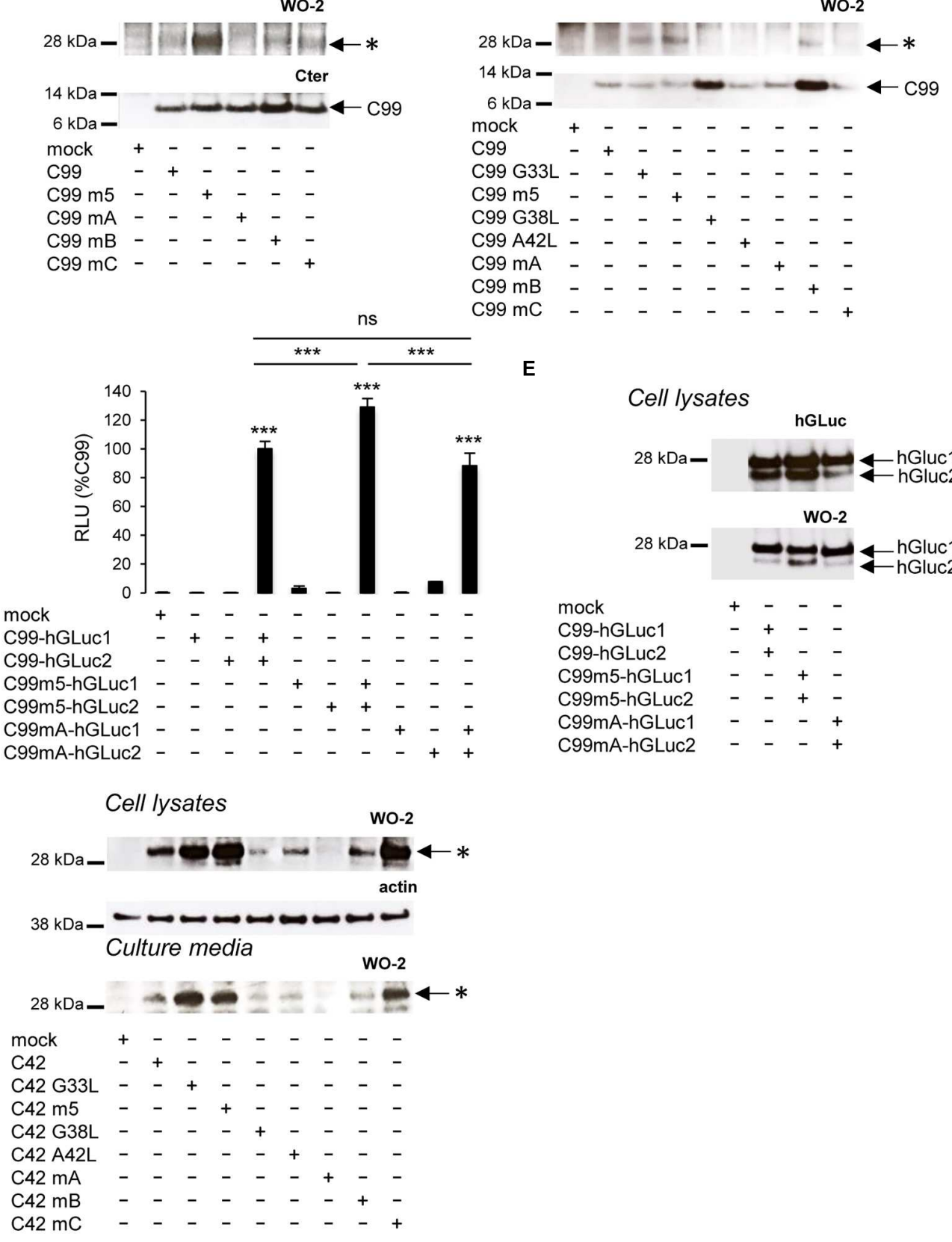


\section{FIGURE 5 | Continued}

Impact of GXXXG/GXXXA mutations on $\mathbf{C 9 9}$ dimerization and A $\boldsymbol{\beta}$ oligomerization. (A) Schematic representation of human the C99 and C42 constructs used. Numbering corresponds to amino acid position in the C99 sequence. The amino acid substitutions generated by site-directed mutagenesis are in red. Glycine and alanine residues of GXXXG/GXXA sequences are underlined. TM, Transmembrane region; ext, extracellular; int, intracellular. (B) Expression of C99 and A $\beta$ oligomers analyzed in cell lysates by Western blotting with the APP C-terminal antibody and the W0-2 antibody, respectively. Oligomers $(*)$ and C99 are indicated by arrows. (C) Expression of $\mathrm{C} 99$ and A $\beta$ oligomers analyzed in lysates of cells expressing the different C99 mutants by Western blotting with the W0-2 antibody. Oligomers $\left(^{*}\right)$ and C99 are indicated by an arrow. (D,E) Dimerization of C99 and C99 mutants (m5, mA) was measured in living cells by the split-luciferase complementation assay. Cells were transfected with C99-coding sequences fused to two hGLuc moieties (hGluc1 and 2, see Figure 1). Bioluminescence (luciferase activity) was measured as RLU and given as percentage of bioluminescence detected in cells co-expressing C99-hGLuc1 and C99-hGLuc2. Values (means \pm SEM) are representative of three independent experiments $\left(n=4\right.$ in each experiment). ${ }^{* * *} p<0.001$, n.s. (non-significant), as compared to control (mock-transfected cells). Expression of the fusion proteins was checked in cell lysates by Western blotting with the hGLuc antibody and the W0-2 antibody. (F) Analysis of A $\beta$ oligomerization was monitored by Western blotting with the W0-2 antibody in cell lysates or culture media of cells expressing C42 or C42 mutants. Actin was used as loading probe (cell lysates). Oligomers $\left(^{*}\right)$ are indicated by an arrow.

C99 were introduced in C42 (Figure 5A). Mutation of glycine residues from the $\mathrm{G}^{29} \mathrm{XXXG}^{33}$ and $\mathrm{G}^{33} \mathrm{XXXG}^{37}$ motifs, especially the G33L mutation, strongly increased the production of $A \beta$ oligomers, which migrated at the same size as C99-derived oligomers (Figures 5B,C). Mutation of small residues (G/A) of the $\mathrm{G}^{38} \mathrm{XXXA}^{42}$ motif abolished oligomerization (Figure 5F). Strikingly, the single G38L mutation decreased oligomerization of C42, and the G38L mutation in the context of G33L $(\mathrm{mB})$ strongly impaired oligomerization of G33L mutants. On the other hand, the A42L mutation had moderate effects and was not able to counteract the increased oligomerization induced by $\mathrm{G} 33 \mathrm{~L}$ mutation $(\mathrm{mC})$. The oligomers detected had the same electrophoretic profile in cell lysates and culture media, confirming the idea that oligomers are formed in cells and released into the culture medium. The critical residues for A $\beta$ oligomerization are G33 and G38. G33L mutation strongly promotes oligomerization; G38L blocks it with a dominant effect on $\mathrm{G} 33$ residue modification.

\section{Oligomeric A $\beta 42$ Peptides Affect Neuronal Differentiation}

One important question was to understand whether the oligomers we found to be produced in living cells and released in the extracellular medium displayed pathological properties. A growing number of studies indicate that the pathological properties of $A \beta$ are directly related to the formation of particular oligomeric assemblies (Benilova et al., 2012). We used the culture medium of $\mathrm{CHO}$ cells transfected with $\mathrm{C} 42, \mathrm{C} 42 \mathrm{~m} 5$, and $\mathrm{C} 42 \mathrm{~mA}$ to treat neuronal NG108-15 cells when differentiation is induced (Figure 6A). Culture media recovered from transfected $\mathrm{CHO}$ cells (after $24 \mathrm{~h}$ of conditioning) showed the $\mathrm{A} \beta$ oligomeric profile detailed above: oligomeric $\mathrm{A} \beta$ was found in $\mathrm{C} 42$-expressing cells, at higher levels in cells expressing C42m5, but not in those expressing C42mA. All had the same electrophoretic profile. NG108-15 cells were treated for 5 days with CHO cell medium, renewed every $48 \mathrm{~h}$. At the end of the treatment, oligomeric bands of $A \beta$ were readily detectable in medium of treated NG108-15 cells (Figure 6B). Five days after treatment, control cells showed the typical neurite outgrowth of differentiated NG108-15 cells (Stanga et al., 2015) measured by MAP2 staining (Figures 6C,D). NG108-15 cells treated with medium from C42and $\mathrm{C} 42 \mathrm{~m} 5$-expressing $\mathrm{CHO}$ cells showed altered differentiation and reduced neurite outgrowth. The intensity of MAP2 staining was particularly reduced in cells treated with media from $\mathrm{C} 42 \mathrm{~m} 5$ expressing cells, in which the highest concentration of $\mathrm{A} \beta$ oligomers was detected. In contrast, the differentiation pattern of cells treated with media of C42mA-expressing cells, in which no oligomeric $\mathrm{A} \beta$ is detected, was comparable to that of non-treated cells. Thus, differentiation and neurite outgrowth of NG108-15 cells is impaired by the presence of $A \beta$ oligomers. Importantly, this is not simply linked to cytotoxicity of these oligomers since the treatments did not affect NG108-15 cell survival in all the conditions tested (Figure 6E). Together, these data highlight an intrinsic property of specific $\mathrm{A} \beta$ oligomers to disrupt the formation of a neuronal network, which might be a very early event in $\beta$-amyloid pathologies.

\section{DISCUSSION}

Our major findings are as follows: (i) expression of a construct coding for a peptide corresponding to $A \beta 42$ leads to the formation of oligomers of $28-30 \mathrm{kDa}$ (with no detection of monomeric $\mathrm{A} \beta 42$ ) that are resistant to denaturation and display neuropathological properties; (ii) the same size oligomer can be detected when C99 ( $\beta$-CTF) is expressed, but in this case a monomeric form can also be detected, suggesting that the location of processing in the cell can influence the extent of oligomerization; (iii) A $\beta 40$ does not induce the formation of such oligomeric species; (iv) the oligomers induced by A $\beta 42$ and C99 are similar, and their size remains identical upon mutation; (v) the formation of oligomers is regulated by the $\mathrm{G}^{29} \mathrm{XXXG}^{33}$ and $\mathrm{G}^{38} \mathrm{XXXA}^{42}$ transmembrane motifs - G33 of the $\mathrm{G}^{29} \mathrm{XXXG}^{33}$ motifs exerts a negative effect and G38 of the GXXXA motif exerts a stimulatory effect on oligomer formation; and (vi) the same motifs also regulate processing of C99 (Kienlen-Campard et al., 2008) without affecting the extent of C99 dimerization in cells.

\section{A $\beta 42$ Oligomers Are Formed in Cells}

The oligomeric peptides revealed by Western blotting that were initially thought to be C99 dimers (Kienlen-Campard et al., 2008) correspond indeed to $A \beta 42$ oligomers. These $A \beta$ oligomers are produced in cells either by the processing of the APP amyloidogenic fragment (C99) to $A \beta$, or when a peptide corresponding to $\mathrm{A} \beta 42$ is expressed in cells. Strikingly, soluble monomeric $\mathrm{A} \beta$ forms are only detected 
A

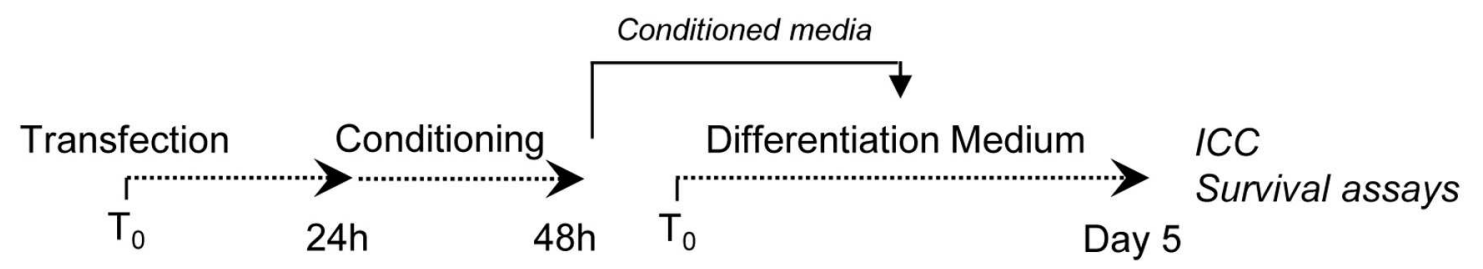

B

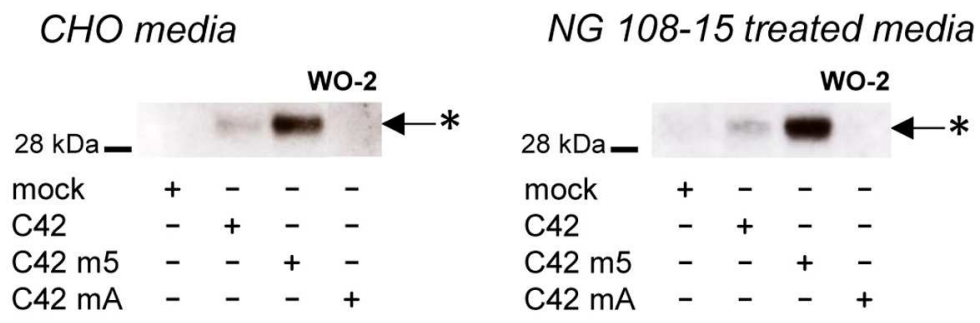

C

MAP2
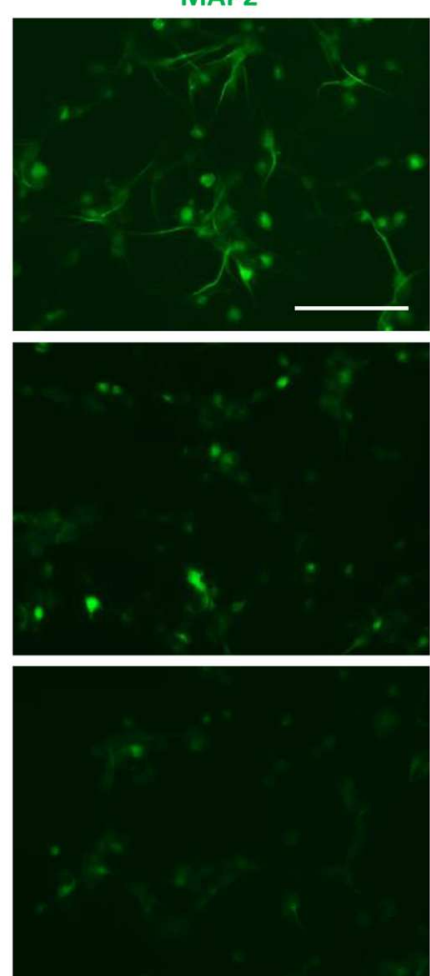

C42 m5

C42 mA

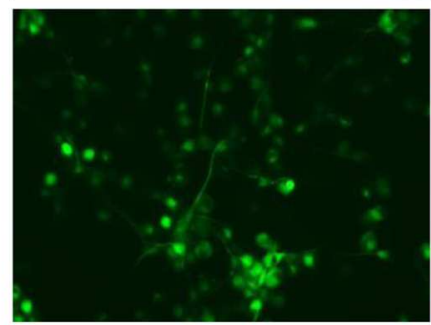

DAPI/MAP2
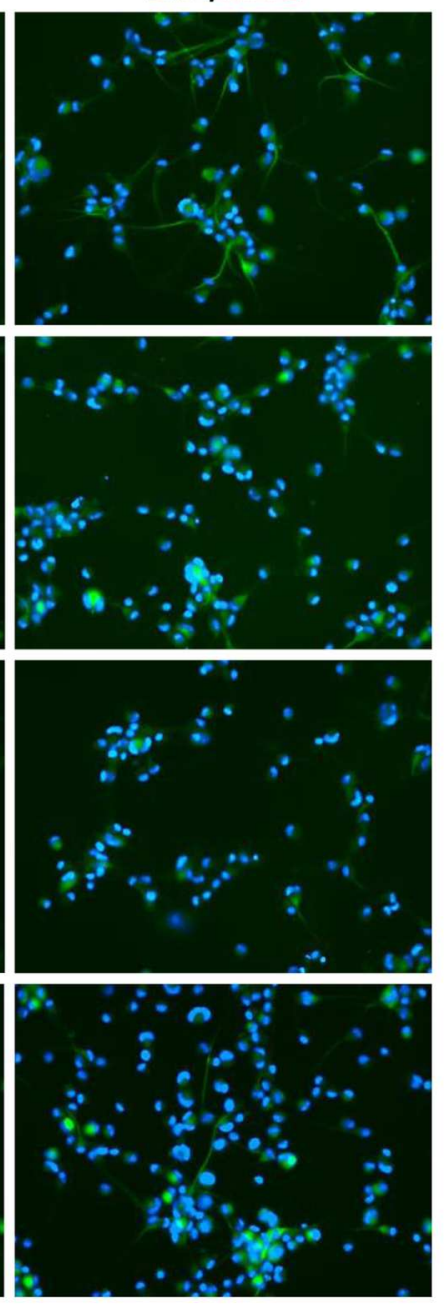

D

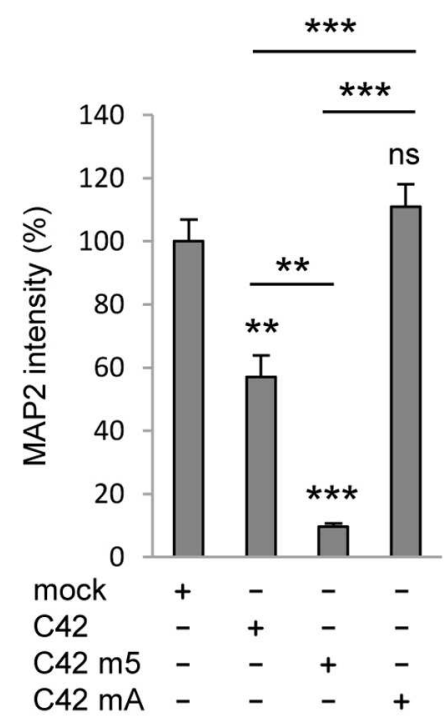

E

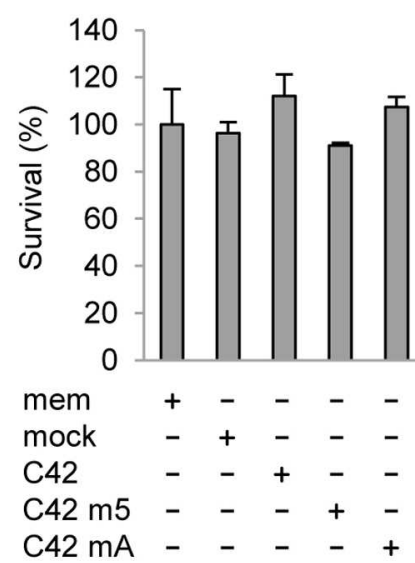




\section{FIGURE 6 | Continued}

Effects of $\mathbf{A} \boldsymbol{\beta}$ oligomers on neuronal cell differentiation and survival. (A) Neuronal NG108-15 cells were treated with media of control $\mathrm{CHO}$ cells (mock) or $\mathrm{CHO}$ cells transfected with $\mathrm{C} 42, \mathrm{C} 42$ mutant $5(\mathrm{~m} 5)$ or $\mathrm{C} 42$ mutant $\mathrm{A}(\mathrm{mA})$ during the differentiation process. (B) The presence of $\mathrm{A} \beta$ oligomers in the media of $\mathrm{CHO}$ producing cells and NG108-15 cells (at day 5) was assessed by Western blotting with the W0-2 antibody. Oligomers $\left(^{*}\right)$ are indicated by arrows. (C) Neuronal differentiation was assessed by immunostaining of NG108-15 treated cells with the MAP2 antibody. Nuclei were stained with the DAPI. Scale: $200 \mu m$.

(D) Quantification of MAP2 immunostaining was performed and expressed as percentage of intensity measured in NG108-15 cells treated with the control medium (mock). Values (means \pm SEM) are representative of three independent experiments ( $n=2$ in each experiment). ${ }^{* * *} p<0.0001,{ }^{* *} p<0.001$, ns (non-significant) as compared to cells treated with the control medium. (E) Survival of the NG108-15 cells was assessed by MTS assay and given as percentage of survival measured in cells treated with the control medium. Values (means \pm SEM) are representative of three independent experiments ( $n=3$ in each experiment). Statistical analysis showed non-significant differences between the conditions.

in C99-expressing cells and not when $\mathrm{A} \beta 42$ is expressed. Thus, the maintenance of soluble $\mathrm{A} \beta 42$ might depend on intracellular compartments where C99 fragments are processed. C42 fragments generate $\mathrm{A} \beta 42$ without being processed by the $\gamma$-secretase. We found that C55 fragments containing the KKK capping motifs at the TM/intracellular junction become substrates for $\gamma$-secretase (Supplementary Figure S4). This observation is quite intriguing and needs to be further investigated, but it suggests that monomeric $A \beta$ can only be produced by specific substrates and in specific compartments, with the short sequence spanning residues $42-55$ being sufficient to localize it to a compartment productive for $\gamma$-secretase cleavage. As soon as these requirements are met, $\mathrm{A} \beta$ shows a high propensity to aggregate, both in cells and in the supernatant. When $\mathrm{A} \beta 42$ is directly produced in cellular compartments (C42 constructs), it spontaneously aggregates to form oligomers; soluble monomeric $A \beta$ is no longer detectable. In this regard, it remains to be determined whether co-expression of $\mathrm{A} \beta 42$ and C99 would allow the detection of soluble $A \beta 42$, would increase the levels of $A \beta 42$ oligomers or promote formation of a higher molecular weight oligomer. The $A \beta$ oligomers we detected are enriched in membrane-bound compartments and found in cell culture medium in conditions where no cytotoxicity is readily measured in $\mathrm{CHO}$ cells. They are thus secreted rather than simply released in the extracellular space upon cell death and subsequent leaking of intracellular components. In addition, we found that intracellular oligomers are not recaptured from the culture medium, or at least at very low levels that cannot be detected in our experimental conditions. This observation strongly supports the conclusion that $A \beta$ oligomers are readily formed in cells and further secreted in the extracellular medium. Intriguingly, only $A \beta$ assemblies of $\sim 25 / 30 \mathrm{kDa}$, corresponding to the expected molecular weight of $\mathrm{A} \beta$ hexamers, can be detected under our experimental conditions. It does not exclude that other $\mathrm{A} \beta$ oligomers are produced by the cells, but their conformation should in this case not be stable enough to withstand with the high temperature denaturing conditions (SDS) we used to run Western blots. The A $\beta$ oligomers we identified are very stable, resistant to SDS, temperature (Supplemental Figure S3) and formic acid denaturation (not shown).

Oligomers were detected only with constructs expressing $\mathrm{A} \beta 42$, and not $\mathrm{A} \beta 40$. $\mathrm{A} \beta 42$, unlike $\mathrm{A} \beta 40$, can form stable trimeric and tetrameric complexes (Chen and Glabe, 2006) as well as globulomer structures (dodecamers) in the presence of SDS (Barghorn et al., 2005), and can form pentamers and hexamers in solution (Bitan et al., 2003; Bernstein et al., 2009). SDS was suggested to artificially produce stable $A \beta$ assemblies. We found $A \beta$ oligomers in the culture media that were not isolated by SDS-based extraction, suggesting that they are not generated by a spurious effect of the detergent. One obvious question is to understand how such $A \beta 42$ oligomers can assemble in cells. Previous studies showed that lowtemperature and low-salt conditions can stabilize disk-shaped oligomers (Ahmed et al., 2010). They do not have the $\beta$-sheet structure characteristic of fibrils, but are rather composed of loosely aggregated strands. Importantly, it has recently been shown that at physiological temperature $\left(37^{\circ} \mathrm{C}\right)$ and at high concentration, $\mathrm{A} \beta 42$ rapidly aggregates into unstructured specific oligomers (Fu et al., 2015). The high concentrations achieved here by direct expression of $\mathrm{A} \beta 42$ could indeed mimic pathological situation in which $A \beta$ accumulates in specific cellular compartments.

\section{G33 and G38 Residues from $\mathrm{G}^{29} \mathrm{XXXG}^{33}$ and $G^{38} X_{X X A^{42}}$ Motifs Dramatically Affect the $A \beta$ Oligomerization Process}

Small amino acid residues (G/A) present in GXXXG or GXXXA motifs are known to promote TM helix association. Their mutation was shown to strongly affect the processing of the $\beta$-CTF (Munter et al., 2007; Kienlen-Campard et al., 2008). Using a protein fragment complementation assay based on Gaussia princeps luciferase, we show that the effects on C99 dimerization of mutating the $\mathrm{G}^{29} \mathrm{XXXG}^{33}$ and $\mathrm{G}^{38} \mathrm{XXXA}^{42}$ motifs are not major. While these motifs might change the precise interface of dimers, they do not control the overall extent of dimerization, at least when measured by the proximity of the C-terminal ends. These results are in line with our recently published work (Decock et al., 2015) showing that the intracellular domain of C99 has a dominant influence on C99 dimerization. GXXXG motifs present in APP TM region might regulate processing of amyloidogenic CTFs either independently of dimerization or by controlling precise dimeric conformations.

We showed that mutation of these glycine residues indeed dramatically affected the formation of $A \beta$ oligomers. G33 and G38 play a predominant role in this process by promoting or blocking oligomerization, respectively. They belong to two different motifs composed of small residues G/A separated by three aminoacids, with G38 being like a pivot. Importantly, identical $\mathrm{A} \beta$ oligomers were detected in cells expressing mutated 
or non-mutated C99 or C42. For the GXXXG mutants, high amounts of oligomers were detected, but no soluble monomeric $\mathrm{A} \beta$ is measured by ECLIA. Soluble monomeric $\mathrm{A} \beta$ was not detected for the different GXXXA mutants, but the mutations in these constructs are at positions preventing detection by the C-terminal ECLIA capture antibody. Our results would suggest that soluble monomeric $A \beta$ is produced by the different mutants, but that the mutations shift the monomeric-oligomeric $A \beta$ equilibrium toward the formation of oligomeric $A \beta$ forms (G33 mutants), or block the conversion from monomers to oligomers (G38 mutants). The turn in the A $\beta$ structure at G38 is a characteristic of $A \beta 42$ oligomers and molecular contacts have been reported in the monomeric unit of $A \beta 42$ fibrils between G38 and F19 (Luhrs et al., 2005) and between M35 and A42 (Masuda et al., 2008). The particular roles of G38 and A42 could first explain the low oligomerization profile of $A \beta$ produced from C99mA and C42mA in which both G38 and A42 are mutated, and the absence of oligomer formation with $\mathrm{A} \beta 40$ lacking the A42 position. G38 is important to form a solvent accessible turn in the $\beta$-hairpin structure of the $A \beta 42$ building blocks assembled in oligomers. G38 to L mutation could thus break the conformation of $\mathrm{A} \beta$ monomers which promotes the formation of oligomers as proposed by Ahmed et al. (2010). G33 residue is part of the $\mathrm{G}^{33} \mathrm{LMVG}^{37}$ hydrophobic sequence forming a $\beta$-strand which is critical for the $A \beta$ monomers to adopt an antiparallel $\beta$-hairpin structure present in $A \beta$ oligomers prior to conversion to $\beta$-sheet structure. Mutation of G33 is thus very likely to modify $A \beta$ conformation in a way that favors oligomerization. Our results are in line with previous studies highlighting G33 as critical for the generation of $A \beta 42$ assemblies (Harmeier et al., 2009). Mutation of G33 was suggested to promote rapid $\mathrm{A} \beta$ oligomerization by conformational changes favoring the formation of high molecular weight oligomers. However, these observations await further structural studies in order to clearly understand how G33 and G38 can contribute to $A \beta$ oligomerization in opposite ways as we observed in cells.

\section{A 342 Oligomers Produced by Cells Display Neuropathological Properties}

Emerging evidence indicates that $A \beta$ oligomers, and not $A \beta$ fibrils, have neuropathological properties. $A \beta$ oligomers can rapidly interact with cell membranes and display neurotoxic effects, before a further possible conversion to protofibrils or fibrils (Ahmed et al., 2010). Apart from cytotoxic effects, $\mathrm{A} \beta$ oligomers have been shown to cause various neuronal dysfunctions. Accumulation of soluble (non-fibrillar) A $\beta$ forms is correlated with the progression of $\mathrm{AD}$ (McLean et al., 1999) and is a predictor of synaptic changes and disruption of neuronal circuits occurring in the pathology (Hsia et al., 1999; Lue et al., 1999). We showed here that $\mathrm{A} \beta$ oligomers released in the cell medium strongly impair neuronal differentiation and neurite outgrowth, but did not display significant neurotoxicity. The neurotoxic effect of $\mathrm{A} \beta 42$ was reported to depend on its intraneuronal accumulation (Kienlen-Campard and Octave, 2002; Bayer and Wirths, 2010), but this is restricted to neurons or primary neuron cultures and does not occur in cell lines (KienlenCampard et al., 2002). Interestingly, we observed intracellular accumulation of $\mathrm{A} \beta$ oligomers in cell lines (CHO) without observing cytotoxic effects. It is very likely that $A \beta$-related cytotoxicity takes place in differentiated post-mitotic neurons, by specific yet poorly understood mechanisms that could involve autophagy. It would be therefore of particular interest to further address $\mathrm{A} \beta 42$ oligomer formation, distribution and cytotoxicity in neurons or neuronal cultures. More specifically, it would be useful to decipher in neuronal model if the toxicity related to intracellular $A \beta$ accumulation involves oligomers, and the precise mechanisms underlying the pathological properties of extracellular $\mathrm{A} \beta$ assemblies. Our results do not exclude that long-time exposure to $A \beta$ oligomers we identified could trigger toxic effects per se. One could also imagine that pathological effects of $A \beta$ oligomers involve specific receptors, among which APP itself (Lorenzo et al., 2000). This could be evaluated in APP deficient (KO) mice models (Heber et al., 2000). All these processes, which need to be further elaborated, could be highly relevant for sporadic Alzheimer's disease where with age the capacity to maintain soluble $A \beta$ decreases and A $\beta 42$ accumulates in neurons as an early event. Previous studies have shown that $A \beta$ concentrated by more than two orders of magnitude can reach micromolar concentrations in acidic vesicular compartments ( $\mathrm{Hu}$ et al., 2009). This local high increase in $A \beta$ concentration could initiate oligomerization in these compartments. Together these observations provide a strong impetus to address the formation and precise subcellular localization of $\mathrm{A} \beta$ oligomers in neurons, and to analyze whether and how they are related to neuronal dysfunction.

However, the fact that $A \beta$ oligomers did not induce cytotoxic effects, but strongly impaired neurite outgrowth and maturation of the neuronal network is in line with previous observations. The extracellular accumulation of a $56-\mathrm{kDa}$ soluble $\mathrm{A} \beta$ oligomer, isolated from brain of $\mathrm{AD}$ transgenic mice, impaired memory independently of any neuronal loss (Lesne et al., 2006). It would be of particular interest to investigate if oligomers identical to the ones we identified here can be isolated from transgenic AD mice or brains of $\mathrm{AD}$ patients. The role of these oligomers on the formation of neurofibrillary tangles (NFTs), another key AD lesion, should also be addressed. Indeed, amyloid deposition has been shown to dramatically aggravate tauopathy in AD mice models (Stancu et al., 2014). It is also important to note that neuronal-specific mechanisms, like post-translational modifications, can participate in $A \beta$ oligomerization. For instance, phosphorylation at different positions, including Ser8 and Ser26, have been shown to enhance or block the formation of $\mathrm{A} \beta$ oligomers in brains (Kumar et al., 2011, 2013). Whether these neuronal mechanisms regulate the $A \beta$ assemblies we identified here should be further explored. Up until now, a puzzling list of $\mathrm{A} \beta$ oligomer species supposed to be multimers of a fundamental $\mathrm{A} \beta$ trimer assembly (hexamers, nonamers, and dodecamers) have been identified from various experimental systems (including human $\mathrm{AD}$ brains and brains of $\mathrm{AD}$ transgenic mice) and isolated under different experimental conditions (Benilova et al., 2012). Still, they provide no clear evidence as to 
which are pathologically relevant, and the molecular mechanisms underlying their precise assembly are poorly understood.

\section{CONCLUSION}

We reported here that specific $A \beta$ oligomeric forms can be produced in living cells, and secreted into the extracellular medium. Such $A \beta$ assemblies are stable, resistant to temperature and SDS denaturation, and impair neuronal maturation and differentiation. They are detected when $A \beta$ is generated upon C99 processing, and are identified at high levels when $A \beta 42$, but not $\mathrm{A} \beta 40$, is directly expressed in cells. We found two glycine residues, G33 and G38, to be critical in $A \beta$ assembly into this oligomer form. Mutation of G33 dramatically increases $\mathrm{A} \beta$ oligomerization, whereas mutation of G38 impairs it. These observations suggest a protective role and a triggering role for G33 and G38 in the A $\beta$ oligomerization process, respectively, and are in line with previous studies highlighting the important role of the $\mathrm{G} 38$ in the $\mathrm{A} \beta$ strand-turn-strand conformation specifically observed in oligomers. In conclusion, our data provide experimental evidence that $\mathrm{A} \beta$ oligomers observed in vitro are readily produced in membranes of living cells, and prompt further investigation into their precise structure, how they assemble, and their pathological relevance to human disease.

\section{AUTHOR CONTRIBUTIONS}

$\mathrm{MD}$ and $\mathrm{PK}-\mathrm{C}$ designed research. $\mathrm{MD}$ and SS conducted experiments. MD, SS, SC, and PK-C analyzed data and wrote the paper with fundamental input of SOS, ID, and J-NO.

\section{FUNDING}

This work was supported by a grant of the Belgian F.N.R.S FRIA (Fonds National pour la Recherche Scientifique) to MD Foundation for Research on Alzheimer's disease (PK-C), by the Interuniversity Attraction Pole Programme-Belgian Sate-Belgian Science Policy (IAP-P7/16 and IAP-P7/13) to J-NO and PK-C, by the Fondation Médicale Reine Elisabeth (FMRE) to J-NO, ID, and PK-C, by the Action de Recherche Concertée (ARC 14/19-059) to PK-C and a grant from the NIH (AG27317) to SS. Support to SC was from the Ludwig Institute for Cancer Research, FRS-FNRS, Salus Sanguinis Foundation, the Action de Recherche Concertée project ARC10/15-027 of the University catholique de Louvain, the Fondation contre le

\section{REFERENCES}

Ahmed, M., Davis, J., Aucoin, D., Sato, T., Ahuja, S., Aimoto, S., et al. (2010). Structural conversion of neurotoxic amyloid-beta(1-42) oligomers to fibrils. Nat. Struct. Mol. Biol. 17, 561-567. doi: 10.1038/nsmb.1799

Barghorn, S., Nimmrich, V., Striebinger, A., Krantz, C., Keller, P., Janson, B., et al. (2005). Globular amyloid beta-peptide oligomer - a homogenous and stable neuropathological protein in Alzheimer's disease. J. Neurochem. 95, 834-847. doi: 10.1111/j.1471-4159.2005.03407.x
Cancer, the PAI Programs BCHM61B5 and Belgian Medical Genetics Initiative.

\section{ACKNOWLEDGMENT}

We are grateful to J-F. Paradis and S.W. Michnick (UMontreal) for the leucine zipper split-luciferase plasmids.

\section{SUPPLEMENTARY MATERIAL}

The Supplementary Material for this article can be found online at: http://journal.frontiersin.org/article/10.3389/fnagi. 2016.00107

FIGURE S1 |Expression of C40 and C42 $\mathrm{mA}$ do not lead to A $\beta$ oligomers formation. Cells were transfected with the control empty vector (mock), or constructs expressing C42 or C40. (A) Analysis of C42/C40 expression and $A \beta$ oligomerization was monitored in cell lysates by Western blotting with the W0-2 antibody. Oligomers (*) are indicated by arrows. (B) Expression of C42 and C40 mRNA levels were measured by RTqPCR with the same primers and given as percentage of mRNA levels measured in C42-expressing cells.

FIGURE S2 | Mass spectrometry analysis of the oligomeric bands produced in C42-expressing cells. Cell lysates from non-transfected (mock) and C42 transfected cell were separated on NuPage gradient gels in denaturating conditions. Gel bands around 30 kDa were excised and proteins were extracted and digested with trypsin. Following digestion, purified peptide samples were analyzed by nanoLC coupled to tandem mass spectrometry (MS/MS). The raw MS file were analyzed and searched against the APP protein sequence database. The results summarized showed the high confidence identification of two peptide sequences contained in the C42/A 342 peptides. $C 42$ and $A \beta 42$ sequences are given on the top of the tables. Peptide sequences identified are in bold. Signal peptide sequence is in blue.

FIGURE S3 | Resistance of A $\boldsymbol{\beta}$ oligomers to temperature. Media of cells expressing $\mathrm{C} 42$ or $\mathrm{C} 42 \mathrm{~m} 5$ were collected and heated at $95^{\circ} \mathrm{C}$ for 0,10 to $30 \mathrm{~min}$ prior to Western blotting revealed with the W0-2 antibody. Oligomers $\left({ }^{*}\right)$ are indicated by an arrow.

FIGURE S4 | A $\beta$ oligomers formation in cells expressing different C-terminal truncations of C99. (A) Schematic representation of the different constructs. C99 corresponds to the APP $\beta$ C-terminal fragment. Numbering corresponds to aminoacid position in the C99 sequence. C55, C49, and C42 have been generated by entering a stop codon at positions 55, 49, and 42 of C99, respectively. TM, Transmembrane region; ext, extracellular; int, intracellular. The aminoacid substitution (referred to as m5) generated for each construct appears in bold and red. (B) Expression of C99, C99 m5, C45 m5, C49 m5, and C55 m5 in $\mathrm{CHO}$ cells analyzed by Western blotting with the WO-2 antibody. Oligomers $\left(^{*}\right)$ and monomers are indicated by arrows. (C) A 338,40 , and 42 were quantified by ECLIA in the culture media of transfected cells. Values (means \pm SEM) given in $\mathrm{pg} / \mathrm{ml}$ are representative of three independent experiments ( $n=3$ in each experiment). ${ }^{*} p<0.05,{ }^{* * *} p<0.001$, as compared to control cells (mock-transfected cells).

Bayer, T. A., and Wirths, O. (2010). Intracellular accumulation of amyloid-Beta - a predictor for synaptic dysfunction and neuron loss in Alzheimer's disease. Front Aging Neurosci. 2:8. doi: 10.3389/fnagi.2010.00008

Ben, K. N., Tyteca, D., Courtoy, P. J., Renauld, J. C., Constantinescu, S. N., Octave, J. N., et al. (2012a). Contribution of Kunitz protease inhibitor and transmembrane domains to amyloid precursor protein homodimerization. Neurodegener. Dis. 10, 92-95. doi: 10.1159/000335225

Ben, K. N., Tyteca, D., Marinangeli, C., Depuydt, M., Collet, J. F., Courtoy, P. J., et al. (2012b). Structural features of the KPI domain control APP dimerization, 
trafficking, and processing. FASEB J. 26, 855-867. doi: 10.1096/fj.11190207

Benilova, I., Karran, E., and De Strooper, B. (2012). The toxic Abeta oligomer and Alzheimer's disease: an emperor in need of clothes. Nat. Neurosci. 15, 349-357. doi: $10.1038 / \mathrm{nn} .3028$

Bernstein, S. L., Dupuis, N. F., Lazo, N. D., Wyttenbach, T., Condron, M. M., Bitan, G., et al. (2009). Amyloid-beta protein oligomerization and the importance of tetramers and dodecamers in the aetiology of Alzheimer's disease. Nat. Chem. 1, 326-331. doi: 10.1038/nchem.247

Bitan, G., Kirkitadze, M. D., Lomakin, A., Vollers, S. S., Benedek, G. B., and Teplow, D. B. (2003). Amyloid beta -protein (Abeta) assembly: Abeta 40 and Abeta 42 oligomerize through distinct pathways. Proc. Natl. Acad. Sci. U.S.A. 100, 330-335. doi: 10.1073/pnas.222681699

Chen, Y. R., and Glabe, C. G. (2006). Distinct early folding and aggregation properties of Alzheimer amyloid-beta peptides Abeta40 and Abeta42: stable trimer or tetramer formation by Abeta42. J. Biol. Chem. 281, 24414-24422. doi: 10.1074/jbc.M602363200

Decock, M., El, H. L., Stanga, S., Dewachter, I., Octave, J. N., Smith, S. O., et al. (2015). Analysis by a highly sensitive split luciferase assay of the regions involved in APP dimerization and its impact on processing. FEBS Open Bio 5, 763-773. doi: 10.1016/j.fob.2015.09.002

Feyt, C., Kienlen-Campard, P., Leroy, K., N'Kuli, F., Courtoy, P. J., Brion, J. P., et al. (2005). Lithium chloride increases the production of amyloid-beta peptide independently from its inhibition of glycogen synthase kinase 3. J. Biol. Chem. 280, 33220-33227. doi: 10.1074/jbc.M501610200

Feyt, C., Pierrot, N., Tasiaux, B., Van Hees, J., Kienlen-Campard, P., Courtoy, P. J., et al. (2007). Phosphorylation of APP695 at Thr668 decreases gamma-cleavage and extracellular Abeta. Biochem. Biophys. Res. Commun. 357, 1004-1010. doi: 10.1016/j.bbrc.2007.04.036

Fonte, V., Dostal, V., Roberts, C. M., Gonzales, P., Lacor, P. N., Velasco, P. T., et al. (2011). A glycine zipper motif mediates the formation of toxic beta-amyloid oligomers in vitro and in vivo. Mol. Neurodegener. 6, 61. doi: 10.1186/17501326-6-61

Fu, Z., Aucoin, D., Davis, J., Van Nostrand, W. E., and Smith, S. O. (2015). Mechanism of Nucleated Conformational Conversion of Abeta42. Biochemistry 54, 4197-4207. doi: 10.1021/acs.biochem.5b00467

Glenner, G. G., and Wong, C. W. (1984). Alzheimer's disease: initial report of the purification and characterization of a novel cerebrovascular amyloid protein. Biochem. Biophys. Res. Commun. 120, 885-890. doi: 10.1016/S0006291X(84)80190-4

Haas, C., Hung, A. Y., Citron, M., Teplow, D. B., and Selkoe, D. J. (1995). Betaamyloid, protein processing and Alzheimer's disease. Arzneimittelforschung 45, 398-402.

Hage, S., Marinangeli, C., Stanga, S., Octave, J. N., Quetin-Leclercq, J., and Kienlen-Campard, P. (2013). Gamma-secretase inhibitor activity of a Pterocarpus erinaceus extract. Neurodegener. Dis. 14, 39-51. doi: 10.1159/0003 55557

Hage, S., Stanga, S., Marinangeli, C., Octave, J. N., Dewachter, I., QuetinLeclercq, J., et al. (2015). Characterization of Pterocarpus erinaceus kino extract and its gamma-secretase inhibitory properties. J. Ethnopharmacol. 163, 192-202. doi: 10.1016/j.jep.2015.01.028

Hardy, J. (2009). The amyloid hypothesis for Alzheimer's disease: a critical reappraisal. J. Neurochem. 110, 1129-1134. doi: 10.1111/j.14714159.2009.06181.x

Hardy, J., and Allsop, D. (1991). Amyloid deposition as the central event in the aetiology of Alzheimer's disease. Trends Pharmacol. Sci. 12, 383-388. doi: 10.1016/0165-6147(91)90609-V

Harmeier, A., Wozny, C., Rost, B. R., Munter, L. M., Hua, H., Georgiev, O., et al. (2009). Role of amyloid-beta glycine 33 in oligomerization, toxicity, and neuronal plasticity. J. Neurosci. 29, 7582-7590. doi: 10.1523/JNEUROSCI.133609.2009

Hayden, E. Y., and Teplow, D. B. (2013). Amyloid beta-protein oligomers and Alzheimer's disease. Alzheimers Res. Ther. 5, 60. doi: 10.1186/ alzrt226

Heber, S., Herms, J., Gajic, V., Hainfellner, J., Aguzzi, A., Rulicke, T., et al. (2000). Mice with combined gene knock-outs reveal essential and partially redundant functions of amyloid precursor protein family members. J. Neurosci. 20, 7951-7963.
Herrup, K. (2015). The case for rejecting the amyloid cascade hypothesis. Nat. Neurosci. 18, 794-799. doi: 10.1038/nn.4017

Hsia, A. Y., Masliah, E., McConlogue, L., Yu, G. Q., Tatsuno, G., Hu, K., et al. (1999). Plaque-independent disruption of neural circuits in Alzheimer's disease mouse models. Proc. Natl. Acad. Sci. U.S.A. 96, 3228-3233. doi: 10.1073/pnas.96.6.3228

Hu, X., Crick, S. L., Bu, G., Frieden, C., Pappu, R. V., and Lee, J. M. (2009). Amyloid seeds formed by cellular uptake, concentration, and aggregation of the amyloid-beta peptide. Proc. Natl. Acad. Sci. U.S.A. 106, 20324-20329. doi: 10.1073/pnas.0911281106

Hung, L. W., Ciccotosto, G. D., Giannakis, E., Tew, D. J., Perez, K., Masters, C. L., et al. (2008). Amyloid-beta peptide (Abeta) neurotoxicity is modulated by the rate of peptide aggregation: Abeta dimers and trimers correlate with neurotoxicity. J. Neurosci. 28, 11950-11958. doi: 10.1523/JNEUROSCI.391608.2008

Kandimalla, R. J., Anand, R., Veeramanikandan, R., Wani, W. Y., Prabhakar, S., Grover, V. K., et al. (2014). CSF ubiquitin as a specific biomarker in Alzheimer's disease. Curr. Alzheimer Res. 11, 340-348. doi: $10.2174 / 1567205011666140331161027$

Kandimalla, R. J., Prabhakar, S., Binukumar, B. K., Wani, W. Y., Gupta, N., Sharma, D. R., et al. (2011). Apo-Eepsilon4 allele in conjunction with Abeta42 and tau in CSF: biomarker for Alzheimer's disease. Curr. Alzheimer Res. 8, 187-196. doi: 10.2174/156720511795256071

Kandimalla, R. J., Wani, W. Y., Binukumar, B. K., and Gill, K. D. (2012). siRNA against presenilin 1 (PS1) down regulates amyloid beta42 production in IMR-32 cells. J. Biomed. Sci. 19, 2. doi: 10.1186/1423-0127-19-2

Kang, J., Lemaire, H. G., Unterbeck, A., Salbaum, J. M., Masters, C. L., Grzeschik, K. H., et al. (1987). The precursor of Alzheimer's disease amyloid A4 protein resembles a cell-surface receptor. Nature 325, 733-736. doi: 10.1038/325733a0

Kawarabayashi, T., Younkin, L. H., Saido, T. C., Shoji, M., Ashe, K. H., and Younkin, S. G. (2001). Age-dependent changes in brain, CSF, and plasma amyloid (beta) protein in the Tg2576 transgenic mouse model of Alzheimer's disease. J. Neurosci. 21, 372-381.

Kienlen-Campard, P., Miolet, S., Tasiaux, B., and Octave, J. N. (2002). Intracellular amyloid-beta 1-42, but not extracellular soluble amyloid-beta peptides, induces neuronal apoptosis. J. Biol. Chem. 277, 15666-15670. doi: 10.1074/jbc.M200887200

Kienlen-Campard, P., and Octave, J. N. (2002). Correlation between beta-amyloid peptide production and human APP-induced neuronal death. Peptides 23, 1199-1204. doi: 10.1016/S0196-9781(02)00055-4

Kienlen-Campard, P., Tasiaux, B., Van Hees , J., Li, M., Huysseune, S., Sato, T., et al. (2008). Amyloidogenic processing but not amyloid precursor protein (APP) intracellular C-terminal domain production requires a precisely oriented APP dimer assembled by transmembrane GXXXG motifs. J. Biol. Chem. 283, 7733-7744. doi: 10.1074/jbc.M707142200

Kim, W., and Hecht, M. H. (2006). Generic hydrophobic residues are sufficient to promote aggregation of the Alzheimer's Abeta42 peptide. Proc. Natl. Acad. Sci. U.S.A. 103, 15824-15829. doi: 10.1073/pnas.0605629103

Kumar, S., Rezaei-Ghaleh, N., Terwel, D., Thal, D. R., Richard, M., Hoch, M., et al. (2011). Extracellular phosphorylation of the amyloid beta-peptide promotes formation of toxic aggregates during the pathogenesis of Alzheimer's disease. EMBO J. 30, 2255-2265. doi: 10.1038/emboj.2011.138

Kumar, S., Wirths, O., Theil, S., Gerth, J., Bayer, T. A., and Walter, J. (2013). Early intraneuronal accumulation and increased aggregation of phosphorylated Abeta in a mouse model of Alzheimer's disease. Acta Neuropathol. 125, 699-709. doi: 10.1007/s00401-013-1107-8

Lesne, S., Koh, M. T., Kotilinek, L., Kayed, R., Glabe, C. G., Yang, A., et al. (2006). A specific amyloid-beta protein assembly in the brain impairs memory. Nature 440, 352-357. doi: 10.1038/nature04533

Liu, W., Crocker, E., Zhang, W., Elliott, J. I., Luy, B., Li, H., et al. (2005). Structural role of glycine in amyloid fibrils formed from transmembrane alpha-helices. Biochemistry 44, 3591-3597. doi: 10.1021/bi047827g

Lorenzo, A., Yuan, M., Zhang, Z., Paganetti, P. A., Sturchler-Pierrat, C., Staufenbiel, M., et al. (2000). Amyloid beta interacts with the amyloid precursor protein: a potential toxic mechanism in Alzheimer's disease. Nat. Neurosci. 3, 460-464. doi: 10.1038/74833

Lue, L. F., Kuo, Y. M., Roher, A. E., Brachova, L., Shen, Y., Sue, L., et al. (1999). Soluble amyloid beta peptide concentration as a predictor of synaptic 
change in Alzheimer's disease. Am. J. Pathol. 155, 853-862. doi: 10.1016/S00029440(10)65184-X

Luhrs, T., Ritter, C., Adrian, M., Riek-Loher, D., Bohrmann, B., Dobeli, H., et al. (2005). 3D structure of Alzheimer's amyloid-beta(1-42) fibrils. Proc. Natl. Acad. Sci. U.S.A. 102, 17342-17347. doi: 10.1073/pnas.05067 23102

Masuda, Y., Uemura, S., Nakanishi, A., Ohashi, R., Takegoshi, K., Shimizu, T., et al. (2008). Verification of the C-terminal intramolecular beta-sheet in Abeta42 aggregates using solid-state NMR: implications for potent neurotoxicity through the formation of radicals. Bioorg. Med. Chem. Lett. 18, 3206-3210. doi: 10.1016/j.bmcl.2008.04.060

McDonald, R. J., Craig, L. A., and Hong, N. S. (2010). The etiology of age-related dementia is more complicated than we think. Behav. Brain Res. 214, 3-11. doi: 10.1016/j.bbr.2010.05.005

McLean, C. A., Cherny, R. A., Fraser, F. W., Fuller, S. J., Smith, M. J., Beyreuther, K., et al. (1999). Soluble pool of Abeta amyloid as a determinant of severity of neurodegeneration in Alzheimer's disease. Ann. Neurol. 46, 860-866. doi: 10.1002/1531-8249(199912)46:6<860::AID-ANA8 > 3.0. $\mathrm{CO} ; 2-\mathrm{M}$

Munter, L. M., Voigt, P., Harmeier, A., Kaden, D., Gottschalk, K. E., Weise, C., et al. (2007). GxxxG motifs within the amyloid precursor protein transmembrane sequence are critical for the etiology of Abeta42. EMBO J. 26, 1702-1712. doi: 10.1038/sj.emboj.7601616

Pham, E., Crews, L., Ubhi, K., Hansen, L., Adame, A., Cartier, A., et al. (2010). Progressive accumulation of amyloid-beta oligomers in Alzheimer's disease and in amyloid precursor protein transgenic mice is accompanied by selective alterations in synaptic scaffold proteins. FEBS J. 277, 3051-3067. doi: 10.1111/j.1742-4658.2010.07719.x

Sato, T., Kienlen-Campard, P., Ahmed, M., Liu, W., Li, H., Elliott, J. I., et al. (2006). Inhibitors of amyloid toxicity based on beta-sheet packing of Abeta40 and Abeta42. Biochemistry 45, 5503-5516. doi: 10.1021/bi05 $2485 f$

Selkoe, D. J. (2004). Alzheimer disease: mechanistic understanding predicts novel therapies. Ann. Intern. Med. 140, 627-638. doi: 10.7326/0003-4819-140-8200404200-00010

Shankar, G. M., Leissring, M. A., Adame, A., Sun, X., Spooner, E., Masliah, E., et al. (2009). Biochemical and immunohistochemical analysis of an Alzheimer's disease mouse model reveals the presence of multiple cerebral Abeta assembly forms throughout life. Neurobiol. Dis. 36, 293-302. doi: 10.1016/j.nbd.2009.07.021

Stancu, I. C., Ris, L., Vasconcelos, B., Marinangeli, C., Goeminne, L., Laporte, V., et al. (2014). Tauopathy contributes to synaptic and cognitive deficits in a murine model for Alzheimer's disease. FASEB J. 28, 2620-2631. doi: 10.1096/fj.13-246702

Stanga, S., Zanou, N., Audouard, E., Tasiaux, B., Contino, S., Vandermeulen, G., et al. (2015). APP-dependent glial cell line-derived neurotrophic factor gene expression drives neuromuscular junction formation. FASEB J. doi: 10.1096/fj.15-278739 [Epub ahead of print],

Conflict of Interest Statement: The authors declare that the research was conducted in the absence of any commercial or financial relationships that could be construed as a potential conflict of interest.

Copyright (C) 2016 Decock, Stanga, Octave, Dewachter, Smith, Constantinescu and Kienlen-Campard. This is an open-access article distributed under the terms of the Creative Commons Attribution License (CC BY). The use, distribution or reproduction in other forums is permitted, provided the original author(s) or licensor are credited and that the original publication in this journal is cited, in accordance with accepted academic practice. No use, distribution or reproduction is permitted which does not comply with these terms. 